\title{
Effects of Dantrolene on Arrhythmogenicity in Isolated Regional Ischemia-Reperfusion Rabbit Hearts with or without Pacing-Induced Heart Failure
}

\author{
Chung-Chuan Chou, ${ }^{1,2}$ Hui-Ling Lee, ${ }^{3}$ Po-Cheng Chang, ${ }^{1,2}$ Hung-Ta Wo, ${ }^{1}$ \\ Ming-Shien Wen, ${ }^{1,2}$ and San-Jou Yeh ${ }^{1,2}$ \\ ${ }^{1}$ Division of Cardiology, Department of Medicine, Chang Gung Memorial Hospital, Linkou District, Taiwan \\ ${ }^{2}$ Chang Gung University College of Medicine, Taoyuan City, Taiwan \\ ${ }^{3}$ Department of Anesthesia, Chang Gung Memorial Hospital, Taipei, Taiwan \\ Correspondence should be addressed to Chung-Chuan Chou; 2867@cgmh.org.tw
}

Received 10 October 2014; Revised 29 December 2014; Accepted 5 January 2015

Academic Editor: Mohamed Boutjdir

Copyright ( $\odot 2015$ Chung-Chuan Chou et al. This is an open access article distributed under the Creative Commons Attribution License, which permits unrestricted use, distribution, and reproduction in any medium, provided the original work is properly cited.

\begin{abstract}
Dantrolene was reported to suppress ventricular fibrillation (VF) in failing hearts with acute myocardial infarction, but its antiarrhythmic efficacy in regional ischemia-reperfusion (IR) hearts remains debatable. Heart failure (HF) was induced by right ventricular pacing. The IR rabbit model was created by coronary artery ligation for $30 \mathrm{~min}$, followed by reperfusion for $15 \mathrm{~min}$ in vivo in both HF and non-HF groups ( $n=9$ in each group). Simultaneous voltage and intracellular $\mathrm{Ca}^{2+}\left(\mathrm{Ca}_{\mathrm{i}}\right)$ optical mapping was then performed in isolated Langendorff-perfused hearts. Electrophysiological studies were conducted and VF inducibility was evaluated by dynamic pacing. Dantrolene $(10 \mu \mathrm{M})$ was administered after baseline studies. The HF group had a higher VF inducibility than the control group. Dantrolene had both antiarrhythmic (prolonged action potential duration (APD) and effective refractory period) and proarrhythmic effects (slowed conduction velocity, steepened APD restitution slope, and enhanced arrhythmogenic alternans induction) but had no significant effects on ventricular premature beat (VPB) suppression and VF inducibility in both groups. A higher VF conversion rate in the non-HF group was likely due to greater APD prolonging effects in smaller hearts compared to the HF group. The lack of significant effects on VPB suppression by dantrolene suggests that triggered activity might not be the dominant mechanism responsible for VPB induction in the IR model.
\end{abstract}

\section{Introduction}

Reperfusion therapy by thrombolysis or immediate percutaneous coronary intervention is commonly performed for acute myocardial infarction (AMI). However, fatal arrhythmia may occur not only during ischemia but also during reperfusion. It has been reported that intracellular $\mathrm{Ca}^{2+}\left(\mathrm{Ca}_{\mathrm{i}}\right)$ overload is involved in the development of fatal arrhythmias postischemia-reperfusion (IR) injury $[1,2]$. The elevated $\mathrm{Ca}_{\mathrm{i}}$ in IR myocardium may enhance triggered activity [3], thereby contributing to IR arrhythmias [4]. Both IR and heart failure (HF) impair sarcoplasmic reticulum (SR) $\mathrm{Ca}^{2+}$ ATPase pump activity $[5,6]$, which results in decreased $\mathrm{SR} \mathrm{Ca}^{2+}$ load and elevated diastolic $\mathrm{Ca}^{2+}$ to facilitate afterdepolarizations induction and triggered activity [7]. It is reasonable to speculate that prevention of spontaneous $\mathrm{SR} \mathrm{Ca}^{2+}$ leak may improve $\mathrm{Ca}_{\mathrm{i}}$ homeostasis and reduce IR arrhythmias, especially in HF. Dantrolene, a stabilizer of skeletal muscle ryanodine receptor-1, has been reported to suppress diastolic $\mathrm{Ca}^{2+}$ leakage by stabilizing ryanodine receptor- 2 of failing cardiomyocytes [8]. We previously reported that dantrolene is effective in preventing ventricular fibrillation (VF) storm by suppressing ventricular premature beats (VPBs) in isolated failing rabbit hearts with AMI [9]. Ortiz et al. reported that dantrolene protects the myocardium against myocardial stunning and IR arrhythmias in Wistar rat hearts [10]; however, other studies have reported that dantrolene has no significant effects on IR arrhythmia in canine hearts [11] and 
on IR injury in rabbits in vivo [12]. Thus, the effect of dantrolene on arrhythmogenesis in IR hearts remains debatable. The purpose of this study was to examine whether dantrolene has a primary antiarrhythmic effect and the mode of its action in isolated IR rabbit hearts with or without pacing-induced HF. We performed simultaneous membrane voltage $\left(V_{m}\right)$ and $\mathrm{Ca}_{\mathrm{i}}$ mapping to investigate the electrophysiological and $\mathrm{Ca}_{\mathrm{i}}$ changes during dantrolene infusion in Langendorff-perfused rabbit hearts with IR injury.

\section{Materials and Methods}

The research protocol was approved by the Institutional Animal Care and Use Committee of Chang Gung Memorial Hospital (approval number 2009092201) and conformed to the Guide for the Care and Use of Laboratory Animals published by the United States National Institutes of Health. Twenty-two adult New Zealand white rabbits $(2.8-4.2 \mathrm{~kg}$ ) were used in the study. Two rabbits died within 4 weeks of pacing initiation, and the hearts from the remaining 20 rabbits (11 with pacing-induced HF (the HF group) and 9 without pacemaker implantation (non-HF group)) were harvested for IR induction. Two rabbits in the HF group developed VF storm during the ischemia period and were not used for optical mapping studies. Left ventricular (LV) function was assessed by echocardiography at baseline and after 4 weeks of pacing.

2.1. Pacing-Induced HF and IR Model Creation. Rapid right ventricular pacing was used to induce $H F$ as described previously [9]. The IR model was created by the same method used in our previous study [13]. Briefly, the rabbits were premedicated with intramuscular injection of ketamine $(35 \mathrm{mg} / \mathrm{kg})$ and xylazine $(5 \mathrm{mg} / \mathrm{kg})$, intubated and anesthetized with isoflurane. When the rabbits were fully anesthetized and unresponsive to physical stimuli, the chests were opened via a left thoracotomy. An obtuse marginal branch of the left circumflex artery was then ligated halfway between the atrioventricular groove and the cardiac apex for 30 minutes, followed by reperfusion. The limb lead electrocardiogram (ECG) was monitored continuously.

2.2. Optical Mapping of Isolated Rabbit Hearts. After reperfusion for 15 minutes, the hearts were excised and Langendorffperfused with $37^{\circ} \mathrm{C}$ Tyrode's solution (in mmol/L: $\mathrm{NaCl} 125$, $\mathrm{KCl} 4.5, \mathrm{MgCl}_{2}$ 0.25, $\mathrm{NaHCO}_{3} 24, \mathrm{NaH}_{2} \mathrm{PO}_{4}$ 1.8, $\mathrm{CaCl}_{2} 1.8$, glucose 5.5 , and albumin $50 \mathrm{mg} / \mathrm{L}$ ) and equilibrated with $95 \%$ $\mathrm{O}_{2}$ and $5 \% \mathrm{CO}_{2}$ to maintain a $\mathrm{pH}$ of 7.4 . The coronary perfusion pressure was regulated and maintained at $70-80 \mathrm{cmH}_{2} \mathrm{O}$. The hearts were stained with Rhod- $2_{\mathrm{AM}}$ (Molecular Probes, Eugene, OR, USA) for $\mathrm{Ca}_{\mathrm{i}}$ and RH237 (Molecular Probes) for $V_{m}$ mapping. The double-stained hearts were illuminated with a laser at $532 \mathrm{~nm}$ wavelength. The emitted fluorescence was filtered and acquired simultaneously with two chargecoupled device cameras (CA-D1-0128T; Dalsa Inc., Billerica, MA, USA) at 269 frames/second. Digital images $(128 \times$ 128 pixels) were gathered from the epicardium of the LV $\left(25 \times 25 \mathrm{~mm}^{2}\right.$ area $)$, resulting in a spatial resolution of 0.2 $\times 0.2 \mathrm{~mm}^{2}$ per pixel. Motion artifacts were suppressed by
$5 \mu \mathrm{M}$ cytochalasin D. The average fluorescence level $(\bar{F})$ of an individual pixel was first calculated for the duration of recording. The ratio on each pixel was then calculated as $(F-\bar{F}) / \bar{F}$, color-coded with shades of red (depolarization) or blue (repolarization), and animated to show propagation patterns in the mapping field.

2.3. Experimental Protocols. A bipolar catheter was inserted into the right ventricular apex for pacing at twice the threshold. The effective refractory period (ERP) was measured by giving a premature stimulus after 8 beats at a $400 \mathrm{~ms}$ pacing cycle length (PCL). $\mathrm{APD}_{80}$ (APD at $80 \%$ repolarization) restitution curve was constructed, and $\mathrm{APD}_{80}$ and $\mathrm{Ca}_{\mathrm{i}}$ alternans were induced by a dynamic pacing protocol [14]. VF inducibility was defined as the ability to provoke sustained VF ( $>2 \mathrm{~min}$ ) with the dynamic pacing protocol [15]. If VF was not induced by dynamic pacing, burst pacing (PCL of 70-90 ms, $5 \mathrm{~ms}$ pulse width, and $5 \mathrm{~mA}$ current for 3-8 seconds) was used. Three episodes of VF (4 seconds each) were obtained consecutively for dominant frequency (DF) analysis. Defibrillation using epicardial patch electrodes was performed for sustained VF. After the baseline study, dantrolene $(10 \mu \mathrm{M})$ was administered for 20 minutes, and the experimental protocol was repeated.

2.4. Data Analysis. $\mathrm{APD}_{80}$ restitution curves were constructed at selected evenly spaced sites [14]. The maximum slope of $\mathrm{APD}_{80}$ restitution curve was determined after curve fitting by first-order exponential fitting. We used monoexponential fitting to compute the time constant $(\tau)$ of the decay portion of the $\mathrm{Ca}^{2+}$ transient [16] at a PCL of $400 \mathrm{~ms}$. The thresholds of $\mathrm{APD}_{80}$ and $\mathrm{Ca}_{\mathrm{i}}$ alternans were defined as the longest PCL required to produce a $10 \mathrm{~ms}$ difference in $\mathrm{APD}_{80}$ and a $10 \%$ difference in $\mathrm{Ca}_{\mathrm{i}}$ amplitude between consecutive beats, respectively [17]. The phase was considered positive for a short-long APD and a small-large $\mathrm{Ca}_{\mathrm{i}}$ amplitude sequence (color-coded in red) and was negative for a long-short APD and a large-small $\mathrm{Ca}_{\mathrm{i}}$ amplitude sequence (color-coded in green). Spatially discordant alternans (SDA) was evidenced by the presence of both red and green regions separated by a nodal line. The SDA threshold was defined as the longest PCL required to reach the alternans threshold on both sides of a nodal line. To estimate conduction velocity (CV), we measured the distance and conduction time between the earliest activation point and two epicardial points in the non-IR and IR zones, respectively [13]. VPB burden (beats/5 min) was calculated by pseudo-ECG recordings at 0-5 $\mathrm{min}$ (taken as baseline), 5-10 $\mathrm{min}, 10-15 \mathrm{~min}$, and 1520 min during dantrolene infusion to evaluate its effects on VPB suppression.

2.5. Statistics. Continuous variables were expressed as mean \pm standard deviation. One-way repeated measures ANOVA (with post hoc LSD analysis) was performed to evaluate the effects of dantrolene on VPB suppression during the 20minute drug infusion period. Two-way repeated measures ANOVA was performed to evaluate the effects of dantrolene on $\mathrm{APD}_{80}$ (PCL at 300, 200, and $150 \mathrm{~ms}$ ) and CV (PCL at 


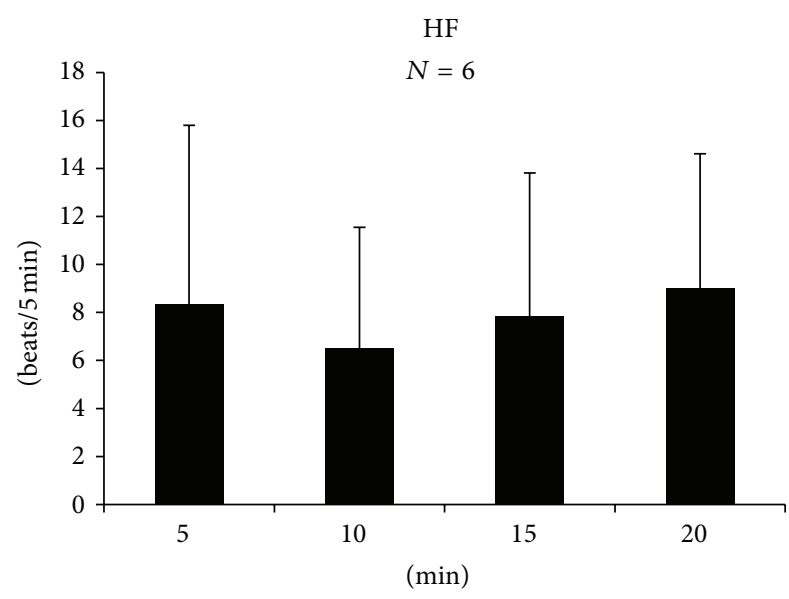

(a)

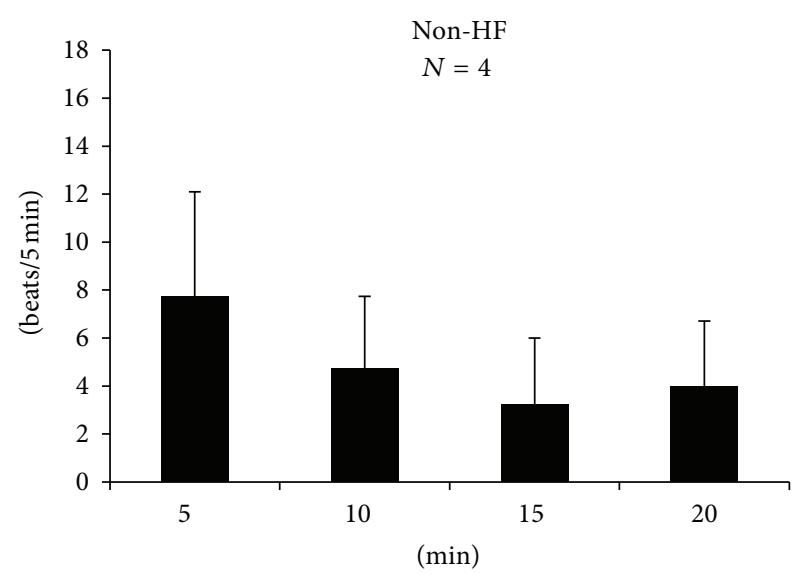

(b)
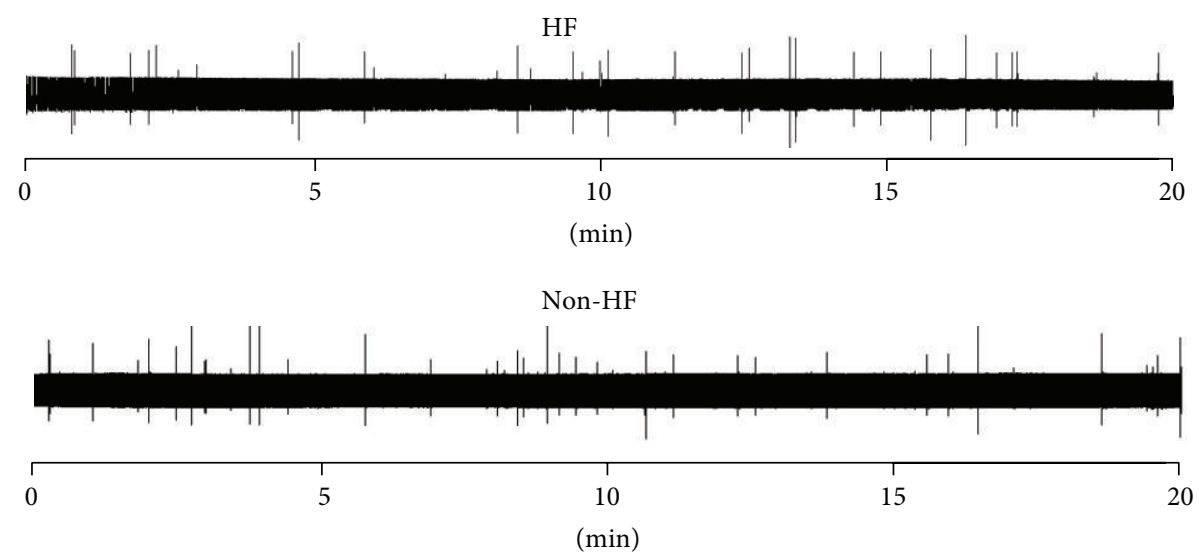

(c)

Figure 1: Dantrolene had no significant effects on suppressing VPBs in the HF (a) and non-HF (b) groups. (c) pseudo-ECG showed no significant decrease of VPBs density (spikes) during dantrolene infusion in either group.

300, 200, 150, and $120 \mathrm{~ms}$ ). The McNemar test was used to compare the VF inducibility at baseline and after dantrolene infusion. A paired $t$-test was used to evaluate statistical significance in ERP, the mean maximum slope of APD restitution, $\mathrm{Ca}_{\mathrm{i}}$ decay, the threshold of alternans and $\mathrm{SDA}$, and the mean maximum DF $\left(\mathrm{DF}_{\max }\right)$ of VF before and after dantrolene treatment in the same hearts. An unpaired $t$-test was performed to compare the $\mathrm{CV}, \mathrm{APD}_{80}$, and $\mathrm{Ca}_{\mathrm{i}}$ decay between the HF and non-HF groups and between the nonIR and IR zones. Generalized estimating equation was used to examine whether the effect of dantrolene on $\mathrm{APD}_{80}$ was significantly different between the HF and non-HF groups. Differences were considered significant when $P<0.05$.

\section{Results}

In the HF group, the mean LV ejection fraction was decreased from $62 \pm 6 \%$ to $29 \pm 7 \%$ after 4 -week rapid pacing $(P<0.01$, $n=9)$. In the non-HF group, the mean LV ejection fraction was $66 \pm 6 \%(n=9)$. The wet weight of the hearts in the HF group ( $21 \pm 4 \mathrm{~g}, n=9)$ was significantly heavier than the nonHF group $(12 \pm 2 \mathrm{~g}, n=9, P<0.001)$.
3.1. Effects of Dantrolene on VPB. In the HF group, 6 of the 9 rabbit hearts had frequent VPBs at baseline $(8.3 \pm$ 7.5 beats $/ 5 \mathrm{~min}$ ); in the non-HF group, 4 of the 9 rabbits hearts had frequent VPBs at baseline $(7.8 \pm 4.3$ beats $/ 5 \mathrm{~min})$. There was no significant difference of baseline VPB burden between two groups $(P>0.05)$. Dantrolene did not lower the frequency of VPB in either groups (Figures 1(a) and 1(b), $P>0.05$ for all comparisons). Figure 1(c) shows examples of pseudo-ECG tracings of a failing (upper) and a control (bottom) heart. The VPB burdens were $9,8,10$, and 9 beats $/ 5 \mathrm{~min}(\mathrm{HF})$ and $12,8,6$, and 8 beats $/ 5 \mathrm{~min}$ (non-HF) at $0-5,5-10,10-15$, and $15-20 \mathrm{~min}$, respectively.

\subsection{Electrophysiological Responses to Dantrolene Administration}

3.2.1. $A P D_{80}$ and ERP. The HF group had a significantly longer $\mathrm{APD}_{80}$ than the control group at $\mathrm{PCL}=300 \mathrm{~ms}(P=$ 0.03) (Table 1). In the HF group, dantrolene prolonged $A P D_{80}$ at PCL $=300 \mathrm{~ms}(P=0.03), 200 \mathrm{~ms}(P=0.03)$, and $150 \mathrm{~ms}$ $(P=0.02)$ and the ERP $(P=0.03)$. In the non-HF group, dantrolene prolonged $\mathrm{APD}_{80}$ at $\mathrm{PCL}=300 \mathrm{~ms}(P=0.003)$, 
TABLE 1: Electrophysiological effects of dantrolene in isolated Langendorff-perfused hearts after IR injury in the HF and non-HF groups.

\begin{tabular}{|c|c|c|c|c|c|c|c|c|c|c|c|}
\hline & $\begin{array}{r}\mathrm{CV}_{(300)} \\
(\mathrm{cm} / \mathrm{s})\end{array}$ & $\begin{array}{l}\mathrm{CV}_{(200)} \\
(\mathrm{cm} / \mathrm{s}) \\
\end{array}$ & $\begin{array}{l}\mathrm{CV}_{(150)} \\
(\mathrm{cm} / \mathrm{s}) \\
\end{array}$ & $\begin{array}{r}\mathrm{CV}_{(120)} \\
(\mathrm{cm} / \mathrm{s})\end{array}$ & $\begin{array}{c}\mathrm{APD}_{(300)} \\
(\mathrm{ms})\end{array}$ & $\begin{array}{c}\mathrm{APD}_{(200)} \\
\quad(\mathrm{ms})\end{array}$ & $\begin{array}{c}\operatorname{APD}_{(150)} \\
(\mathrm{ms})\end{array}$ & $\begin{array}{l}\text { ERP } \\
(\mathrm{ms}) \\
\end{array}$ & $\begin{array}{c}\mathrm{DF}_{\max } \\
(\mathrm{Hz})\end{array}$ & $\begin{array}{c}\text { APDR } \\
\text { slope }\end{array}$ & $\begin{array}{c}\mathrm{Ca}_{\mathrm{i}} \text { decay } \\
(\tau)(\mathrm{ms})\end{array}$ \\
\hline \multicolumn{12}{|l|}{$\operatorname{HF}(n=9)$} \\
\hline Baseline & $72 \pm 12$ & $68 \pm 11$ & $63 \pm 11$ & $55 \pm 9$ & $157 \pm 16$ & $130 \pm 11$ & $108 \pm 10$ & $161 \pm 27$ & $14.2 \pm 1.3$ & $1.14 \pm 0.17$ & $69 \pm 12$ \\
\hline Dantrolene & $67 \pm 10^{*}$ & $61 \pm 11^{*}$ & $55 \pm 10^{*}$ & $47 \pm 6^{*}$ & $169 \pm 20^{*}$ & $135 \pm 12^{*}$ & $110 \pm 8^{*}$ & $182 \pm 12^{*}$ & $11.3 \pm 1.5^{*}$ & $1.34 \pm 0.24^{*}$ & $72 \pm 10$ \\
\hline \multicolumn{12}{|c|}{ Non-HF $(n=9)$} \\
\hline Baseline & $81 \pm 7$ & $76 \pm 9$ & $70 \pm 9$ & $64 \pm 8$ & $148 \pm 9$ & $125 \pm 9$ & $107 \pm 12$ & $142 \pm 11$ & $13.0 \pm 1.7$ & $0.97 \pm 0.19$ & $66 \pm 8$ \\
\hline Dantrolene & $73 \pm 11^{*}$ & $67 \pm 11^{*}$ & $61 \pm 12^{*}$ & $55 \pm 11^{*}$ & $160 \pm 14^{*}$ & $134 \pm 11^{*}$ & $112 \pm 12^{*}$ & $170 \pm 10^{*}$ & $10.4 \pm 1.5^{*}$ & $1.19 \pm 0.30^{*}$ & $67 \pm 8$ \\
\hline
\end{tabular}

Values are mean $\pm \mathrm{SD} . \mathrm{APD}_{(300)}, \mathrm{APD}_{(200)}$, and $\mathrm{APD}_{(150)}$, action potential duration at pacing cycle lengths of 300,200 , and $150 \mathrm{~ms} ; \mathrm{CV}_{(300)}, \mathrm{CV}_{(200)}, \mathrm{CV}_{(150)}$, and $\mathrm{CV}_{(120)}$, conduction velocity at pacing cycle lengths of $300,200,150$, and $120 \mathrm{~ms} ; \mathrm{DF}_{\max }$ : the maximal dominant frequency of ventricular fibrillation; $\mathrm{Ca}_{\mathrm{i}}$ : intracellular $\mathrm{Ca}^{2+}$; ERP: effective refractory period; APDR slope: the mean maximum slope of APD restitution curves.

Asterisks denote values significantly different from the baseline.

TABLE 2: Electrophysiological effects of dantrolene in non-IR and IR zones in HF and non-HF groups.

\begin{tabular}{|c|c|c|c|c|c|c|c|c|c|c|}
\hline & $\begin{array}{l}\mathrm{CV}_{(300)} \\
(\mathrm{cm} / \mathrm{s})\end{array}$ & $\begin{array}{l}\mathrm{CV}_{(200)} \\
(\mathrm{cm} / \mathrm{s})\end{array}$ & $\begin{array}{l}\mathrm{CV}_{(150)} \\
(\mathrm{cm} / \mathrm{s})\end{array}$ & $\begin{array}{l}\mathrm{CV}_{(120)} \\
(\mathrm{cm} / \mathrm{s})\end{array}$ & $\begin{array}{c}\operatorname{APD}_{(300)} \\
(\mathrm{ms})\end{array}$ & $\begin{array}{c}\operatorname{APD}_{(200)} \\
(\mathrm{ms})\end{array}$ & $\begin{array}{c}\operatorname{APD}_{(150)} \\
(\mathrm{ms})\end{array}$ & $\begin{array}{c}\mathrm{DF}_{\max } \\
(\mathrm{Hz})\end{array}$ & $\begin{array}{c}\mathrm{Ca}_{\mathrm{i}} \text { decay } \\
(\tau)(\mathrm{ms})\end{array}$ & $\begin{array}{l}\text { APDR } \\
\text { slope }\end{array}$ \\
\hline \multicolumn{11}{|l|}{$\operatorname{HF}(n=9)$} \\
\hline \multicolumn{11}{|l|}{ Baseline } \\
\hline Non-IR & $76 \pm 11$ & $72 \pm 12$ & $66 \pm 11$ & $57 \pm 7$ & $155 \pm 13$ & $130 \pm 11$ & $109 \pm 10$ & $14.4 \pm 1.6$ & $67 \pm 11$ & $1.14 \pm 0.16$ \\
\hline IR & $70 \pm 9$ & $65 \pm 9$ & $60 \pm 9$ & $55 \pm 9$ & $158 \pm 18$ & $130 \pm 11$ & $108 \pm 11$ & $14.0 \pm 1.3$ & $70 \pm 14$ & $1.13 \pm 0.20$ \\
\hline \multicolumn{11}{|l|}{ Dantrolene } \\
\hline Non-IR & $73 \pm 9$ & $66 \pm 10$ & $61 \pm 9$ & $51 \pm 6$ & $167 \pm 19$ & $135 \pm 11$ & $110 \pm 6$ & $11.7 \pm 1.2$ & $72 \pm 10$ & $1.34 \pm 0.25$ \\
\hline IR & $67 \pm 8$ & $61 \pm 10$ & $54 \pm 9$ & $45 \pm 6^{*}$ & $168 \pm 22$ & $134 \pm 12$ & $109 \pm 8$ & $10.9 \pm 1.8^{*}$ & $73 \pm 10$ & $1.35 \pm 0.26$ \\
\hline \multicolumn{11}{|c|}{ Non-HF $(n=9)$} \\
\hline \multicolumn{11}{|c|}{ Baseline } \\
\hline Non-IR & $84 \pm 6$ & $79 \pm 7$ & $73 \pm 5$ & $69 \pm 5$ & $148 \pm 9$ & $125 \pm 9$ & $107 \pm 11$ & $13.7 \pm 1.3$ & $63 \pm 6$ & $1.02 \pm 0.16$ \\
\hline IR & $78 \pm 7$ & $73 \pm 9$ & $67 \pm 7$ & $63 \pm 7$ & $149 \pm 9$ & $125 \pm 9$ & $108 \pm 12$ & $12.3 \pm 2.2^{*}$ & $69 \pm 8^{*}$ & $0.91 \pm 0.20$ \\
\hline \multicolumn{11}{|l|}{ Dantrolene } \\
\hline Non-IR & $78 \pm 8$ & $70 \pm 8$ & $66 \pm 7$ & $60 \pm 8$ & $162 \pm 15$ & $134 \pm 11$ & $113 \pm 12$ & $11.1 \pm 1.5$ & $65 \pm 7$ & $1.29 \pm 0.38$ \\
\hline IR & $67 \pm 11^{*}$ & $60 \pm 9^{*}$ & $52 \pm 10^{*}$ & $48 \pm 9^{*}$ & $162 \pm 15$ & $134 \pm 11$ & $111 \pm 11$ & $9.7 \pm 1.7^{*}$ & $70 \pm 9^{*}$ & $1.09 \pm 0.25$ \\
\hline
\end{tabular}

Values are mean $\pm \mathrm{SD} . \mathrm{APD}_{(300)}, \mathrm{APD}_{(200)}$, and $\mathrm{APD}_{(150)}$, action potential duration at pacing cycle lengths of 300,200 , and $150 \mathrm{~ms} ; \mathrm{CV}_{(300)}, \mathrm{CV}_{(200)}, \mathrm{CV}_{(150)}$, and $\mathrm{CV}_{(120)}$, conduction velocity at pacing cycle lengths of $300,200,150$, and $120 \mathrm{~ms} ; \mathrm{DF}_{\max }$ : the maximal dominant frequency of ventricular fibrillation; $\mathrm{Ca}_{\mathrm{i}}$ : intracellular $\mathrm{Ca}^{2+} ; \mathrm{CV}$ : conduction velocity.

Asterisks denote values significantly different between non-IR and IR zones.

$200 \mathrm{~ms}(P=0.001)$, and $150 \mathrm{~ms}(P=0.004)$ and the ERP $(P=0.002)$ (Table 1$)$. Generalized estimating equation analysis showed that there was a trend that dantrolene exerted a greater effect on $\mathrm{APD}_{80}$ prolongation in the non-HF group than in the $\mathrm{HF}$ group at $\mathrm{PCL}=150 \mathrm{~ms}(P=0.06)$. There was no significant difference in $\mathrm{APD}_{80}$ between the non-IR and IR zones at baseline or with dantrolene at all PCLs in either group ( $P>0.05$ for all comparisons) (Table 2 ).

3.2.2. $A P D_{80}$ Restitution Slope. There was a tendency of a steeper mean maximum slope of $\mathrm{APD}_{80}$ restitution in the $\mathrm{HF}$ group than in the non-HF group $(P=0.07$, Table 1$)$. There was no significant difference in the mean APD restitution slopes between IR and non-IR at baseline and after dantrolene infusion in either groups $(P>0.05$ for all comparisons, Table 2). Dantrolene steepened the maximum slope of $\mathrm{APD}_{80}$ restitution in the HF group $(P=0.049)$ and the nonHF group $(P=0.027)$ (Figure $2(\mathrm{a}))$. Figure $2(\mathrm{~b})$ shows an example. In a failing heart (left subpanel), the mean maximal $\mathrm{APD}_{80}$ restitution slopes were $1.21 \pm 0.27$ at baseline (blue) versus $1.44 \pm 0.23$ after dantrolene infusion (red) $(P=$ 0.004, $n=18$ points); in a non-HF heart (right subpanel), dantrolene also significantly steepened $\mathrm{APD}_{80}$ restitution slope $(0.96 \pm 0.19$ versus $1.21 \pm 0.16, P<0.001, n=19$ points).

3.2.3. $C V$. The HF group had a slower $\mathrm{CV}$ than the non-HF group at baseline $(P=0.01,0.02,0.02,<0.001$ at PCLs $=$ 300, 200, 150, and $120 \mathrm{~ms}$, resp.). Dantrolene decreased CV at all PCLs in both groups (Table 1), and the differences of CV between the HF and non-HF groups became less significant after dantrolene infusion $(P=0.15,0.22,0.30,0.02$ at PCLs $=$ $300,200,150$, and $120 \mathrm{~ms}$, resp.). In the HF group, there was no significant difference in CV between the IR and nonIR zones at baseline, but CV became significantly slower in the IR zone than the non-IR zone as the PCL decreased to $120 \mathrm{~ms}(P=0.04)$ after dantrolene infusion (Table 2$)$. In 


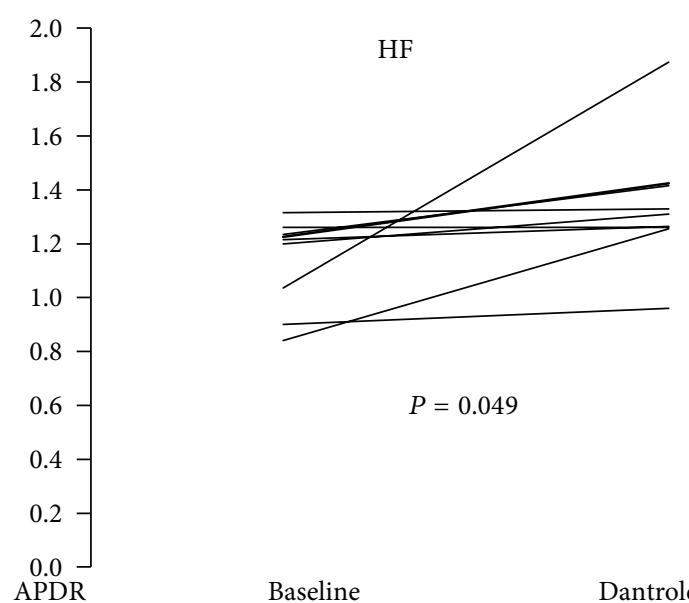

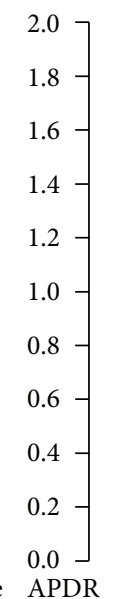

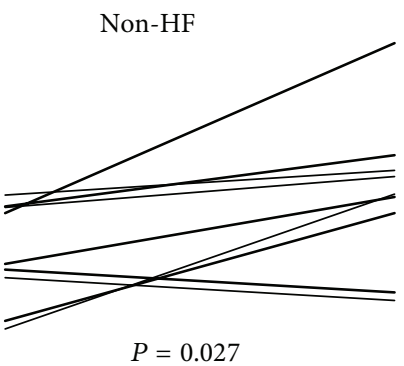

(a)
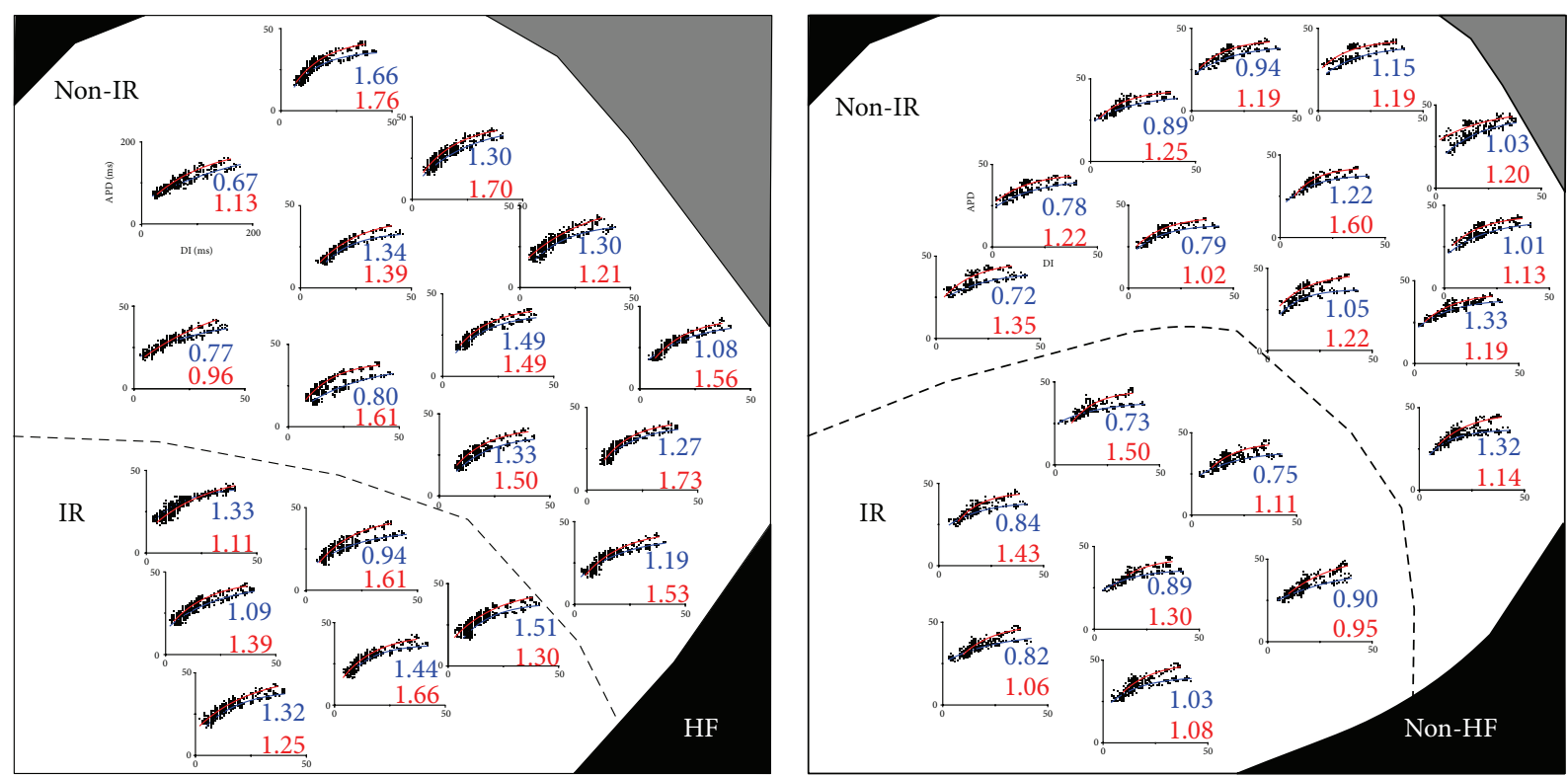

(b)

FIgURE 2: Dantrolene steepened $\mathrm{APD}_{80}$ restitution slopes in both groups. (a) Paired statistics for APD restitution (APDR) slopes. The data points (lines) are averages from each experiment. (b) representative examples of the spatial distribution of APDR curves at baseline (blue) and after dantrolene infusion (red) in both groups. The numbers under each subpanel are the maximum slopes of $\mathrm{APD}_{80}$ restitution at the selected evenly-spaced sites. DI: diastolic interval.

the non-HF group, there was a tendency of slower $\mathrm{CV}$ in the IR than in the non-IR zones at baseline $(P=0.08,0.1$, 0.06, 0.06 at PCLs of $300,200,150$, and $120 \mathrm{~ms}$, resp.), and the differences became significant after dantrolene infusion at all PCLs $(P=0.03,0.04,0.005,0.009$ at PCLs of 300, 200, 150, and $120 \mathrm{~ms}$, resp.) (Table 2). Figure 3(a) shows an example in the HF group. Impulses propagated smoothly at PCLs $>150 \mathrm{~ms}$ but took longer to activate the reperfused region at shorter PCLs $(<150 \mathrm{~ms})$, especially after dantrolene infusion. At baseline, $\mathrm{CV}$ (PCL $=300 \mathrm{~ms}$ versus $120 \mathrm{~ms}$ ) was decreased from $77 \mathrm{~cm} / \mathrm{s}$ to $62 \mathrm{~cm} / \mathrm{s}$ in the non-IR zone and from $77 \mathrm{~cm} / \mathrm{s}$ to $61 \mathrm{~cm} / \mathrm{s}$ in the IR zone. After dantrolene infusion, $\mathrm{CV}$ (PCL $=300 \mathrm{~ms}$ versus $120 \mathrm{~ms}$ ) was decreased from $72 \mathrm{~cm} / \mathrm{s}$ to $50 \mathrm{~cm} / \mathrm{s}$ in the non-IR zone and from $66 \mathrm{~cm} / \mathrm{s}$ to $46 \mathrm{~cm} / \mathrm{s}$ in the IR zone in this heart. Figure 3(b) shows an example of the non-HF group. At baseline, CV (PCL = $300 \mathrm{~ms}$ versus $120 \mathrm{~ms}$ ) was decreased from $93 \mathrm{~cm} / \mathrm{s}$ to $72 \mathrm{~cm} / \mathrm{s}$ in the non-IR zone and from $82 \mathrm{~cm} / \mathrm{s}$ to $68 \mathrm{~cm} / \mathrm{s}$ in the IR zone. After dantrolene infusion, $\mathrm{CV}$ (PCL $=300 \mathrm{~ms}$ versus $120 \mathrm{~ms}$ ) was decreased from $86 \mathrm{~cm} / \mathrm{s}$ to $52 \mathrm{~cm} / \mathrm{s}$ in the non-IR zone and from $70 \mathrm{~cm} / \mathrm{s}$ to $47 \mathrm{~cm} / \mathrm{s}$ in the IR zone in this heart. In addition, $\mathrm{CV}$ alternans was induced by rapid pacing, which played a role in facilitating SDA induction.

3.2.4. Alternans and $\mathrm{SDA} . \mathrm{APD}_{80}$ and $\mathrm{Ca}^{2+}$ transient alternans were in synchrony in all mapped episodes (an example shown in Figure 5(c)). Dantrolene significantly lowered the pacing rate threshold for alternans induction in both groups (HF: $200 \pm 30 \mathrm{~ms}$ (baseline) versus $222 \pm 36 \mathrm{~ms}$ (dantrolene), $P=0.02, n=9$; non-HF: $187 \pm 11 \mathrm{~ms}$ (baseline) versus 
HF

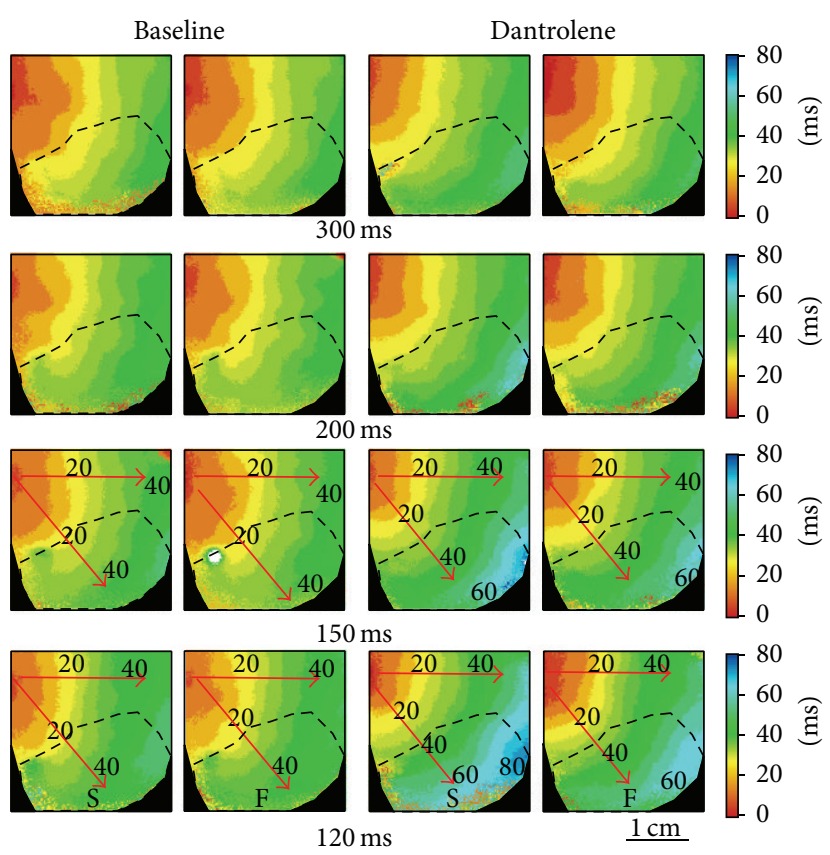

(a)

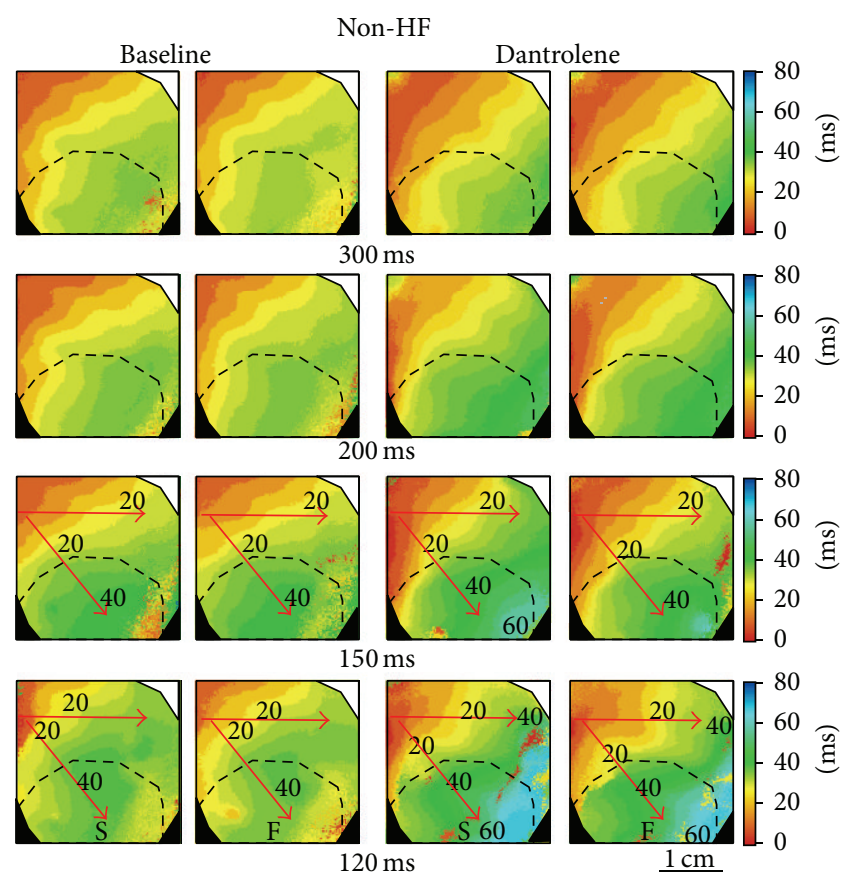

(b)

FIGURE 3: Effects of dantrolene on CV and anisotropic conduction. (a) and (b) are representative examples of isochronal maps in the HF and non-HF groups, respectively. Rate-dependent conduction slowing is shown in both groups. The number under each subpanel is the PCL. Dashed lines indicate the border of IR zone; red arrows indicate the directions of wavefront propagation. S: slow; F: fast.

$237 \pm 30 \mathrm{~ms}$ (dantrolene), $P<0.001, n=9$ ). In addition, the threshold of SDA was lowered by dantrolene in both groups (HF: $120 \pm 17 \mathrm{~ms}$ (baseline) versus $141 \pm 16 \mathrm{~ms}$ (dantrolene), $P<0.001, n=9$; non-HF: $126 \pm 11 \mathrm{~ms}$ (baseline) versus $147 \pm 13 \mathrm{~ms}$ (dantrolene), $P=0.01, n=7$ ).

3.2.5. $C a_{i}$ Decay. Dantrolene had no significant effects on $\mathrm{Ca}_{\mathrm{i}}$ reuptake in either group (Table 1). In the HF group, there was no significant difference in the $\tau$ values between the IR and non-IR zones at baseline or after dantrolene infusion $(P>$ 0.05 for all comparisons) (Table 2). A representative example is provided in Figure 4(a). The mean $\tau$ values (non-IR versus IR) were $71 \pm 7 \mathrm{~ms}$ and $72 \pm 6 \mathrm{~ms}$ at baseline and $72 \pm 5 \mathrm{~ms}$ and $74 \pm 6 \mathrm{~ms}$ after dantrolene infusion in this failing heart. In the non-HF group, $\mathrm{Ca}_{\mathrm{i}}$ decay was significantly slower in the IR zone than in the non-IR zone at baseline $(P=0.007)$ and after dantrolene infusion $(P=0.03)$ (Table 2$)$. As shown in Figure 4(b), the mean $\tau$ values (non-IR versus IR) were $64 \pm$ $2 \mathrm{~ms}$ and $71 \pm 5 \mathrm{~ms}$ at baseline and $64 \pm 2 \mathrm{~ms}$ and $70 \pm 5 \mathrm{~ms}$ after dantrolene infusion in this non-HF heart.

3.3. Effects of Dantrolene on VF Induction and Maintenance. The HF group had a higher VF inducibility than the non-HF group at baseline ( 7 of 9 versus 2 of $9, P=0.03$ ). Almost all pacing-induced VF episodes (including burst pacing) were sustainable in the HF ( 9 of 9 ) and non-HF (8 of 9) groups at baseline. Dantrolene had no significant effects on VF inducibility ( 7 of 9 versus 7 of $9, P=\mathrm{NS}$ ) or VF maintenance ( 9 of 9 versus 6 of $9, P=\mathrm{NS}$ ) in the HF group. In the non-HF group, the VF inducibility was borderline increased (2 of 9 versus 6 of $9, P=0.125$ ), but VF became less sustainable ( 8 of 9 versus 3 of $9, P=0.0498$ ) after dantrolene infusion.

Figure 5 shows an example of dantrolene effects on VF dynamics in the HF group. In this failing heart, VF was not induced during dynamic pacing at baseline $(\mathrm{PCL}=90 \mathrm{~ms}$, Figure 5(a), left subpanel), even if CV alternans (Figure 5(b)) and SDA (from PCL $=120 \mathrm{~ms}$, Figure 5(c)) were induced. After dantrolene infusion, VF was induced by dynamic pacing $(\mathrm{PCL}=90 \mathrm{~ms}$ ) but converted to VT spontaneously (Figure 5(a), right subpanel). Figure 5(d) shows that rapid pacing induced functional conduction block to form figure8 reentry (frames 320,416 , and $508 \mathrm{~ms}$ ), and the conduction delay caused wavefronts to arise from the opposite side of the IR border to activate the IR zone and collide with the original wavefronts to perpetuate VF (frame $760 \mathrm{~ms}$ ) (see online video 1 in Supplementary Material available online at http://dx.doi.org/10.1155/2015/532820). However the VF was not sustainable. As shown in Figure 5(e), the breakthrough wavefronts could not propagate into the IR zone directly (frames 1768, $1884 \mathrm{~ms}$ ). The functional conduction block simplified the wavefront propagation pattern and converted VF to VT (online video 2). SDA was induced at a longer PCL after dantrolene infusion (from $140 \mathrm{~ms}$, Figure 5(e), right subpanel), and the nodal lines corresponded to the lines of functional conduction block as shown in Figures 5(d) and 5(e). In the HF group, VF was converted to ventricular tachycardia (VT) in 2 hearts and converted to sinus rhythm in 1 heart. 


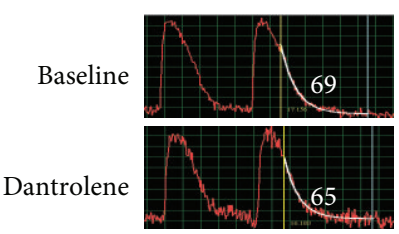

(A)

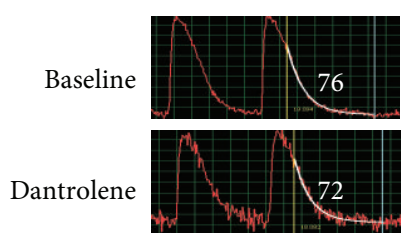

(E)

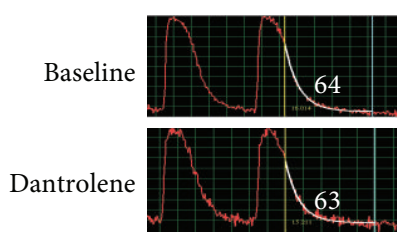

(A)

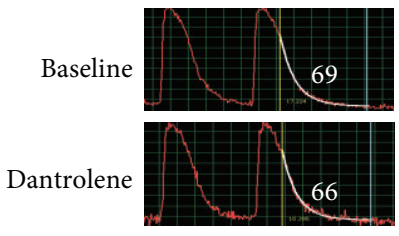

(E)

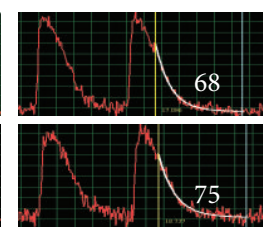

(B)

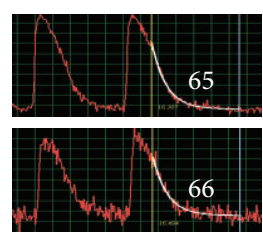

(F)

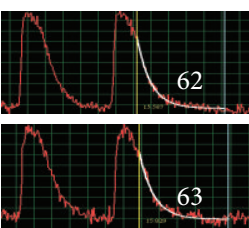

(B)

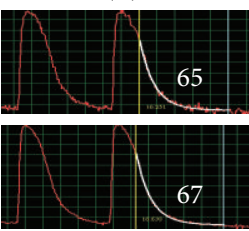

(F)

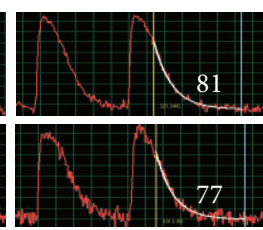

(C)
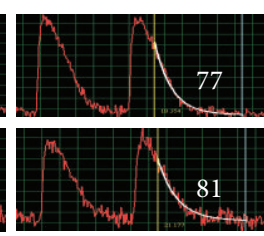

(G)

(a)

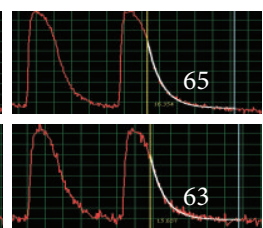

(C)

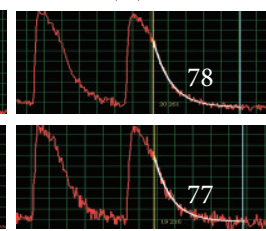

(G)

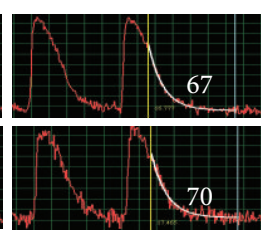

(D)

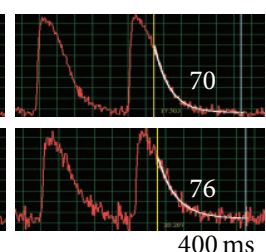

(H)

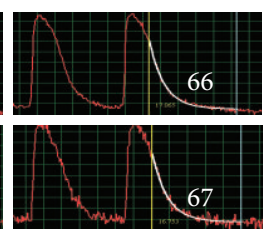

(D)

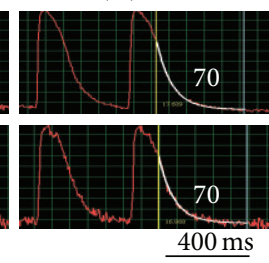

(H)

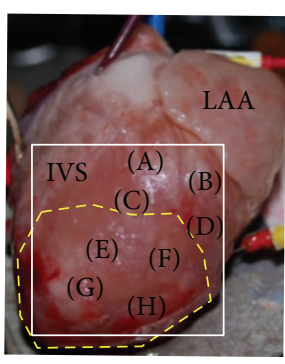

HF

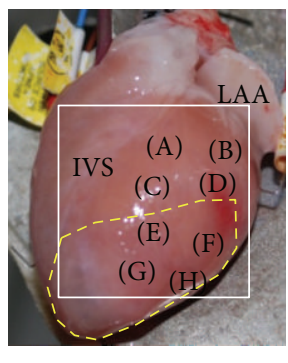

Non-HF

(b)

FIGURE 4: Effects of dantrolene on $\mathrm{Ca}_{\mathrm{i}}$ decay. (a) and (b) representative examples of the distribution of $\mathrm{Ca}^{2+}$ decay time in the non-IR and IR zones at baseline and during dantrolene infusion in the HF and non-HF groups, respectively. Dantrolene had no significant effects on $\mathrm{Ca}_{\mathrm{i}}$ delay in either group. The number on each subpanel is the $\tau$ value (ms). The right subpanel illustrates the mapping field, and (A) to (H) indicate sites where the $\mathrm{Ca}_{\mathrm{i}}$ decay time was measured. LAA: left atrial appendage; IVS: interventricular sulcus.

In the non-HF group, VF was converted to VT and then stopped $(n=4)$ or directly converted to sinus rhythm $(n=2)$ in 6 hearts with nonsustained VF after dantrolene infusion. Figure 6 shows an example. At baseline, sustained VF was induced as PCL decreased to $100 \mathrm{~ms}$, and electrical defibrillation was needed to convert it (data not shown). After dantrolene infusion, VF was induced at a longer PCL but terminated spontaneously 49 seconds after induction. As shown in Figure 6(a) ( $V_{m}$ tracings), APD alternans was induced (at PCL $=120 \mathrm{~ms}$ ) before VF induction. The corresponding isochronal maps (Figure 6(c)) show pacinginduced CV alternans and crowded isochronal lines (white arrows, frames 68 to $452 \mathrm{~ms}$ ) at PCL $=120 \mathrm{~ms}$. A longer $\mathrm{APD}$ was correlated to a slower $\mathrm{CV}$, indicating that $\mathrm{CV}$ was controlled at least partly by APD (ERP) at faster pacing rates. When PCL was shortened to $110 \mathrm{~ms}$, the pacing wavefront met a line of functional conduction block (frames 564 and $672 \mathrm{~ms}$ ) to form reentry and perpetuated VF (frames 776 and $860 \mathrm{~ms}$ ) (online video 3). Figure 6(b) $\left(V_{m}\right.$ tracings) and Figure 6(d) (snapshots) show spontaneous VF termination. A wavefront met a line of functional conduction block to form figure-8 reentry (snapshots 796 to $948 \mathrm{~ms}$ ), but the new-formed wavefronts were blocked (snapshot $1008 \mathrm{~ms}$ ), followed by a wavefront arising from the border of the IR zone (white arrow, snapshot $1036 \mathrm{~ms}$ ) and then a wavefront from the border of the mapping field (snapshots 1204 to $1396 \mathrm{~ms}$ ) before conversion to sinus rhythm (online video 4). Figure 6(e) shows that SDA was induced by rapid pacing (PCL $120 \mathrm{~ms}$, left subpanel), and a new nodal line (red arrow, right subpanel) was formed as the PCL decreased to $110 \mathrm{~ms}$. These nodal lines corresponded to the lines of functional conduction block shown in Figures 6(c) and 6(d) and played an important role in wavelet generation and annihilation.

The $\mathrm{DF}_{\max }$ of VF was significantly decreased by dantrolene infusion (Table 1). In the HF group, the difference of $\mathrm{DF}_{\max }$ between the IR and non-IR zones was not significant at baseline ( $P=0.23, n=9$, Table 2$)$; however, it became significant with dantrolene infusion $(P=0.008, n=9$, Table 2). In the non-HF group, the IR zone had a lower $\mathrm{DF}_{\max }$ than the non-IR zone at baseline $(P=0.01, n=9)$ and after dantrolene infusion ( $P=0.009, n=9$, Table 2$)$. As shown in Figure 6(f), the mean values of the $\mathrm{DF}_{\max }$ of VF 

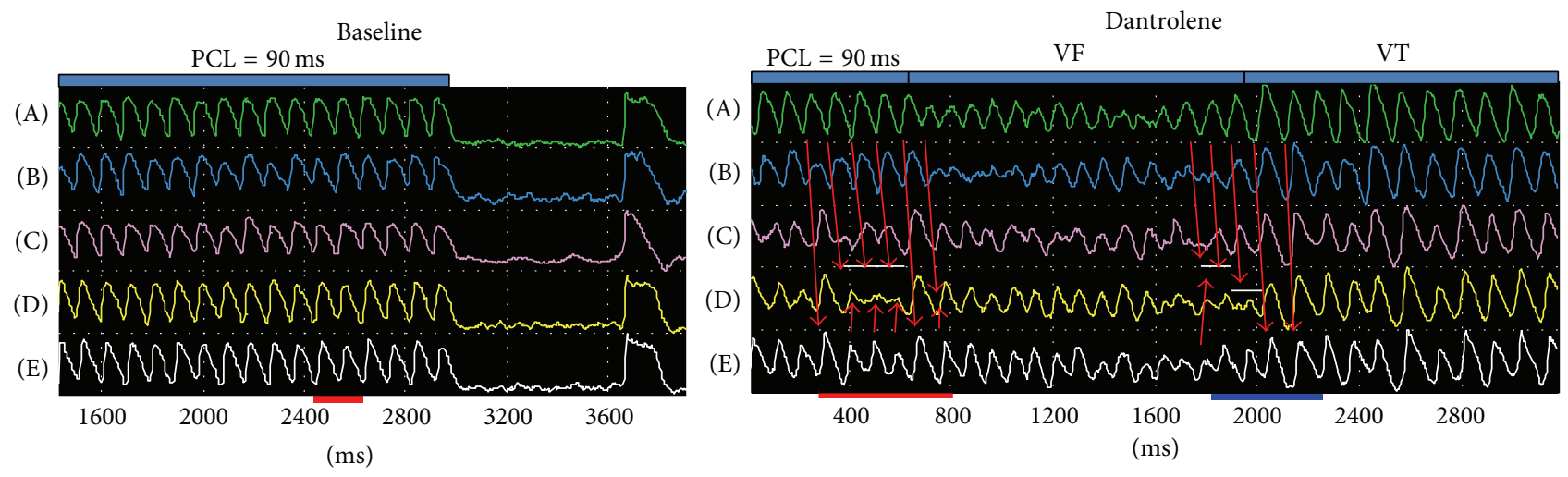

(a)

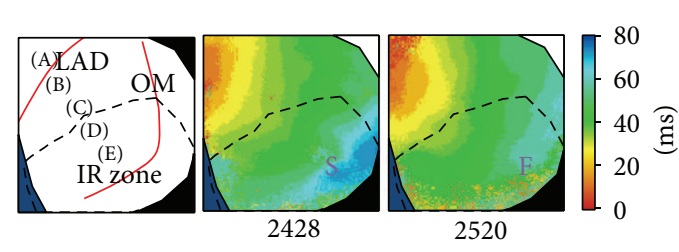

(b)

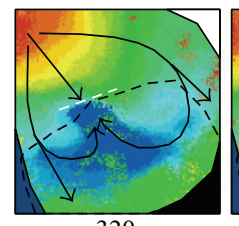

320

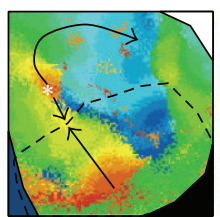

1768

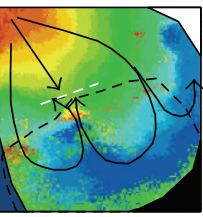

416

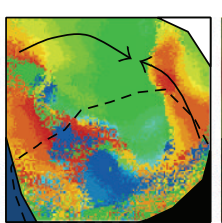

1792

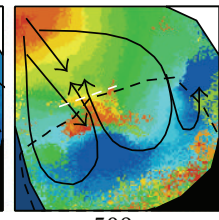

508

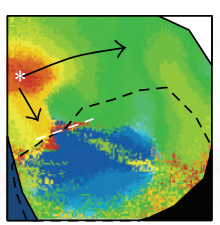

1884

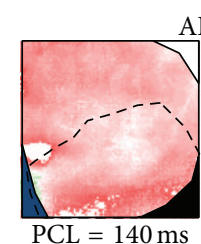

$\mathrm{PCL}=140 \mathrm{~ms}$

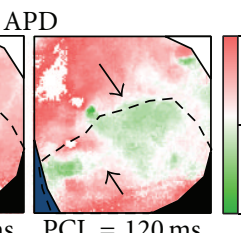

PCL $=120 \mathrm{~ms}$
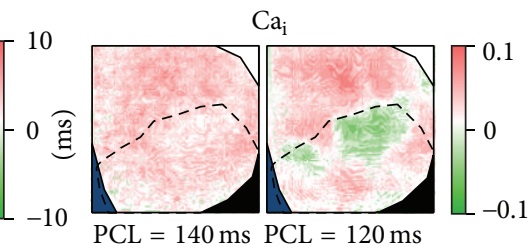

(c)
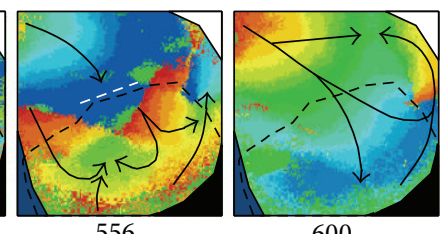

600

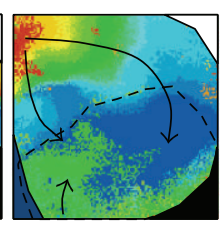

680

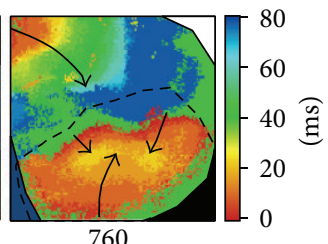

(d)

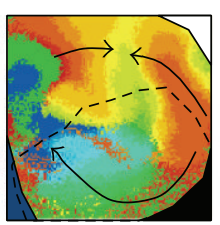

1904

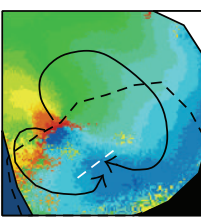

1976

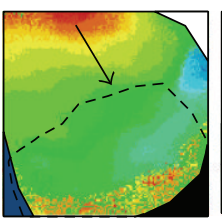

2108

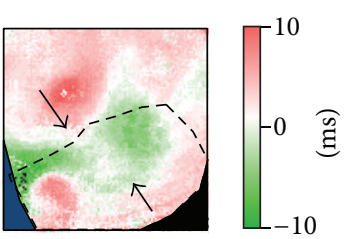

$\mathrm{PCL}=140 \mathrm{~ms}$

(e)

FIGURE 5: VF induction and VF conversion to VT during dantrolene administration in a failing heart. (a) $V_{m}$ tracings corresponding to the points labeled in panel (b) during rapid pacing $(\mathrm{PCL}=90 \mathrm{~ms}$ ) at baseline (left subpanel) and with dantrolene (right subpanel). The red arrows indicate wavefront propagation and the white lines indicate conduction block. (b) Schematic illustration of the mapped region (left subpanel) and isochronal maps (right subpanels) corresponding to two consecutive beats labeled in panel (a) (left subpanel, red bar). (c) Ca $\mathrm{a}_{\mathrm{i}}$ and APD alternated in synchrony. SDA was not induced at PCL $=140 \mathrm{~ms}$ until it was shortened to $120 \mathrm{~ms}$ at baseline but was induced at PCL $=140 \mathrm{~ms}$ with dantrolene infusion (panel (e), right subpanel). The black arrows indicate nodal lines. (d) and (e) isochronal maps of VF initiation and VF conversion to VT corresponding to the period labeled in panel (a) (right subpanel and red and blue bars, resp.). The white dashed lines indicate functional conduction block; white asterisks indicate focal breakthrough.

were $12.4 \pm 0.5 \mathrm{~Hz}$ at baseline and $9.9 \pm 0.9 \mathrm{~Hz}$ with dantrolene. The non-IR zone had a higher mean $\mathrm{DF}_{\max }$ of VF than that in the IR zone at baseline $(12.7 \pm 0.5 \mathrm{~Hz}$ versus $12.0 \pm 0.4 \mathrm{~Hz})$ and with dantrolene infusion $(10.6 \pm 0.8 \mathrm{~Hz}$ versus $9.2 \pm 0.4 \mathrm{~Hz})$. This suggests a driven rather than a driver role of the IR zone in VF dynamics in this model.

\section{Discussion}

We studied the effects of dantrolene on suppression of VPB and VF inducibility in post-IR injury hearts with and without pacing-induced HF. The major results were that dantrolene did not suppress spontaneous VPBs and VF inducibility in either group. Dantrolene exerted antiarrhythmic action via prolonging APD and ERP, which may underlie a higher VF conversion rate in smaller hearts in the non-HF group. But the APD and ERP lengthening effect also intensified the rate-dependent conduction delay; in addition, dantrolene steepened APD restitution properties and facilitated both spatially concordant and discordant alternans induction, all of which may oppose its antiarrhythmic effects. 


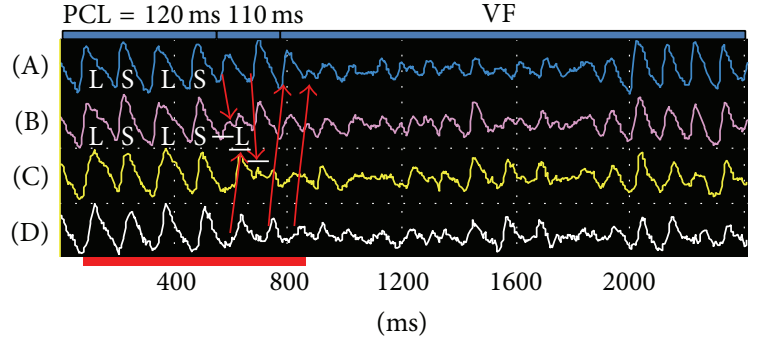

(a)
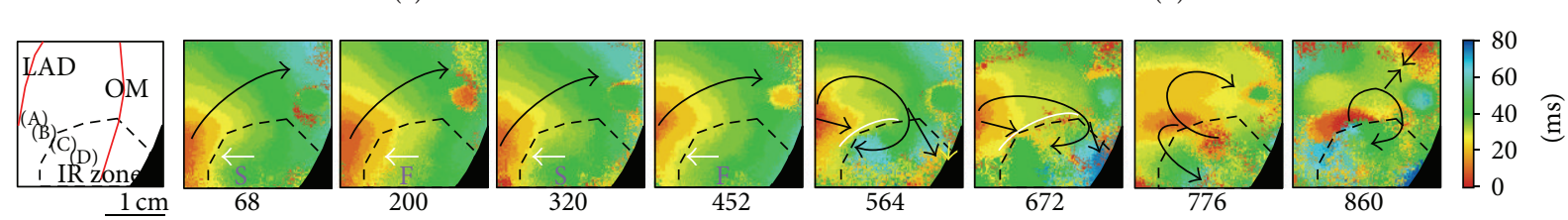

(c)
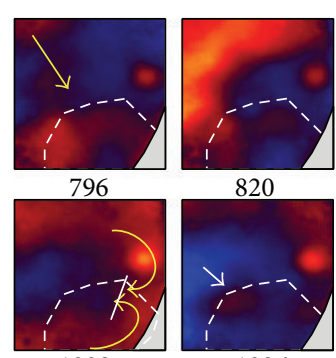

1008

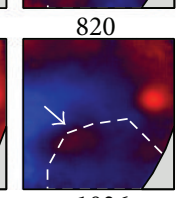

1036
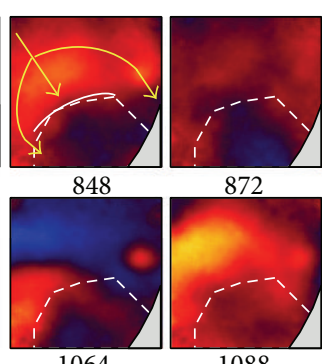

872
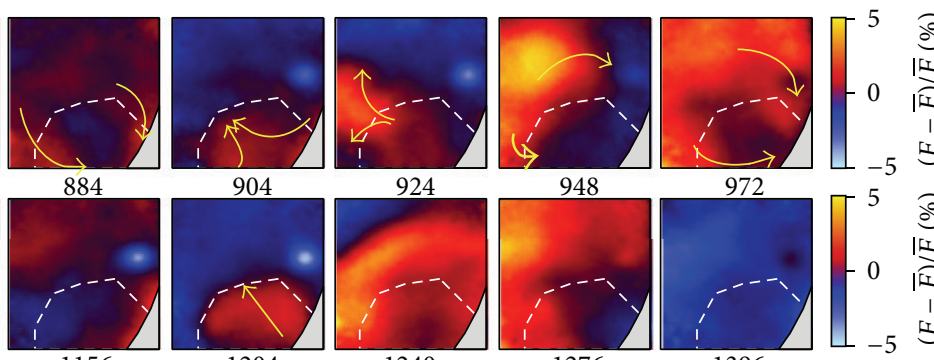

1204
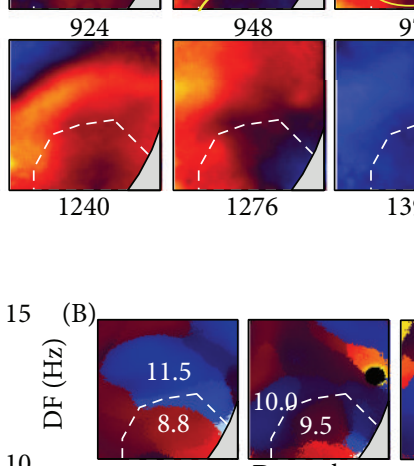

Dantrolene
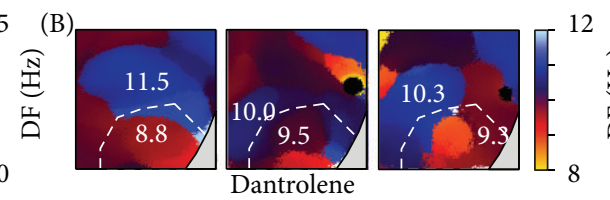

(e) (f)

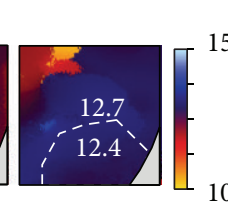

FIGURE 6: VF induction and spontaneous termination during dantrolene administration in a non-HF heart. (a) and (b) $V_{m}$ tracings corresponding to the points labeled in panel (c) during VF induction and VF termination, respectively. The red arrows indicate wavefront propagation, and the white lines indicate conduction block. L: long; S: short. (c) Isochronal maps corresponding to the period labeled in panel (a) showing CV alternans followed by conduction block and VF initiation. The white lines indicate functional conduction block. (d) Frame shots corresponding to the period labeled in panel. (b) The white lines indicate lines of functional conduction block, and the white arrow indicates focal breakthrough. (e) APD difference maps showing SDA induction. The black and red arrows indicate nodal lines. (f) The dominant frequency (DF) maps of induced VF at baseline (A) and after dantrolene infusion (B). SR: sinus rhythm.

4.1. VPB Suppression in IR Hearts. We previously reported that dantrolene was effective in suppressing VPBs via decreasing diastolic SR $\mathrm{Ca}^{2+}$ oscillations in an AMI with HF model [9]. In post-IR injury hearts, Sharma et al. reported that reperfusion for 30 minutes resulted in a significant increase in tissue $\mathrm{Ca}^{2+}$ in the IR zone [18]. Since a reduced binding affinity of calmodulin to ryanodine receptor-2 fitted for dantrolene's action on SR is found in failing hearts rather than normal hearts [19], dantrolene would be predicted to suppress VPBs in the IR model, especially in the HF group. However, our data did not show a decreased VPB burden during dantrolene infusion neither in HF group nor in non-HF group. There are some possible explanations. First, as Vera et al. reported [20], triggered activity may not be the dominant mechanism responsible for VPBs in IR hearts. Yee et al. noted only small-amplitude oscillatory afterpotentials during reperfusion but no triggered activity, which cast doubt on whether triggered activity is a mechanism of reperfusion arrhythmias [21]. On the other hand, enhanced automaticity has been reported to be the dominant mechanism of VPBs in post-IR injury hearts [22]. The lack of a VPB suppressing effect by dantrolene could be due to its inability to suppress automaticity $[23,24]$. Second, if triggered activity is the dominant mechanism of VPBs, it implies that dantrolene could not ameliorate the $\mathrm{Ca}_{\mathrm{i}}$ overload condition effectively in these IR hearts. Temsah et al. reported that the attenuated recovery of contractile function and $\mathrm{Ca}_{\mathrm{i}}$ overload post-IR injury are due to reduced SR $\mathrm{Ca}^{2+}$ uptake, $\mathrm{Ca}^{2+}$ release, 
and ryanodine-binding activities [25]. Therefore, suppression of diastolic $\mathrm{SR} \mathrm{Ca}^{2+}$ leakage alone may not be sufficient to improve $\mathrm{Ca}_{\mathrm{i}}$ overload conditions.

\subsection{Dantrolene on Conduction Delay in the IR Rabbit Model.} Penkoske et al. reported that reperfusion arrhythmias are initiated by enhanced pacemaker activity and maintained by localized and slowed conduction within IR regions [26]. Both the IR-induced downregulation of $\mathrm{Na}^{+}$channel [27] and reduced gap junction conductance as a result of the elevated $\mathrm{Ca}_{\mathrm{i}}$ of the IR myocardium may account for a depressed conduction in the IR region [28]. Salata et al. reported that dantrolene has no significant effect on upstroke velocity of phase 0 but prolongs APD mediated in part by a decrease in the intracellular free $\mathrm{Ca}^{2+}$ concentration $[23,29]$. Therefore, dantrolene can either ameliorate conduction depression by decreasing intracellular free $\mathrm{Ca}^{2+}$ concentration (to improve gap junction conductance) or further decelerate $\mathrm{CV}$ via prolonging APD (as impulses traveling through partially refractory tissue). Our data showed that dantrolene deteriorated conduction delay and led to frequency-dependent functional conduction block, which may play a role in facilitating VF induction (as shown in Figures 5 and 6). However, the worsening of conduction delay was caused by APD prolongation, which neutralized its arrhythmogenicity by hindering wavelet propagation to stop VF (as shown in Figure 6).

4.3. Anti- and Proarrhythmic Effects of Dantrolene on IR Hearts. Dantrolene prolongs APD, which by itself can decrease the $\mathrm{DF}_{\max }$ of VF and influence the persistence of VF through its effects on wavelength [30]. However, the electrophysiological studies and mapping data also showed that dantrolene has proarrhythmic effects (i.e., slowing CV, steepening APD restitution slope, and lowering the pacing threshold of arrhythmogenic alternans induction) in the IR model. These effects have been demonstrated to create functional electrophysiological dispersion that destabilizes wave propagation and enhances the tissue vulnerability to initiate reentry $[31,32]$. The lack of significant effects of dantrolene on the VF inducibility and maintenance in the HF group might be due to a counterbalance of its antiarrhythmic and proarrhythmic effects. On the other hand, dantrolene had a higher VF conversion rate in the non-HF group, which is likely due to a greater APD prolonging effect in smaller hearts in the non-HF group compared with the HF group. Salata et al. demonstrated that dantrolene prolongs APD, possibly mediated by inhibiting L-type $\mathrm{Ca}^{2+}$ channels, subsequently depressing $\mathrm{Ca}^{2+}$-sensitive potassium channels [29]. Because L-type $\mathrm{Ca}^{2+}$ channels are impaired in pacinginduced HF [33], it is possible that fewer L-type $\mathrm{Ca}^{2+}$ channels are available to respond to the inhibitory effect of dantrolene, resulting in a less degree of APD prolongation in the HF group.

4.4. Clinical Implications. Dantrolene has been shown to prevent VF storm in failing hearts with AMI [9]. However, the presented data suggest that dantrolene has no significant effects on VF inducibility and maintenance in failing hearts post-IR injury. The clinical benefits of continuous dantrolene use in HF patients with AMI and VF storm postreperfusion therapy are not obvious and may require further investigations.

4.5. Study Limitations. Given that the electrophysiological studies were performed with Langendorff perfusion, it is possible that electrophysiological parameters may be different when the hearts are in situ and also caution is advised when extrapolating our model to clinical IR cardiac injury. Because the $\mathrm{Ca}^{2+}$ amplitude of optical signals was a ratio derived from the difference of $\mathrm{Ca}^{2+}$ dye fluorescence intensity between the peak and the trough of acquired beats rather than the absolute value of intracellular $\mathrm{Ca}^{2+}$ concentration changes, we could not make comparisons of the absolute $\mathrm{Ca}^{2+}$ amplitude between the optical signals acquired at different moments (baseline versus after dantrolene). Therefore, whether the amplitude of $\mathrm{Ca}^{2+}$ transient was affected by dantrolene was not shown in this study. The estimated CV slowing in the IR zone might be underestimated since the initial portion of IR distance measurement (from the earliest activation point to the IR zone border) was in the non-IR zone. We did not perform patch clamp studies and measure gap junction conductance; therefore, whether dantrolene exerted a direct inhibition effect on sodium current and/or gap junction coupling was not shown in this study.

\section{Disclosure}

The authors take responsibility for all aspects of the reliability and freedom from bias of the data presented and their discussed interpretation.

\section{Conflict of Interests}

The authors have no potential conflict of interests to disclose.

\section{Acknowledgment}

This work was supported by Chang Gung Memorial Hospital Medical Research Programs [CMRPG38154] and [CMRPG3C1651] to Chung-Chuan Chou.

\section{References}

[1] D. J. Hearse, "Reperfusion of the ischemic myocardium," Journal of Molecular and Cellular Cardiology, vol. 9, no. 8, pp. 605616, 1977.

[2] U. Limbruno, R. Zucchi, S. Ronca-Testoni, P. Galbani, G. Ronca, and M. Mariani, "Sarcoplasmic reticulum function in the "stunned" myocardium," Journal of Molecular and Cellular Cardiology, vol. 21, no. 10, pp. 1063-1072, 1989.

[3] P. B. Corr and F. X. Witkowski, "Potential electrophysiologic mechanisms responsible for dysrhythmias associated with reperfusion of ischemic myocardium," Circulation, vol. 68, no. 2, pp. 16-24, 1983. 
[4] L. H. Opie and W. A. Coetzee, "Role of calcium ions in reperfusion arrhythmias: relevance to pharmacologic intervention," Cardiovascular Drugs and Therapy, vol. 2, no. 5, pp. 623-636, 1988.

[5] C. L. Overend, D. A. Eisner, and S. C. O’Neill, "Altered cardiac sarcoplasmic reticulum function of intact myocytes of rat ventricle during metabolic inhibition," Circulation Research, vol. 88, no. 2, pp. 181-187, 2001.

[6] U. Schmidt, R. J. Hajjar, P. A. Helm, C. S. Kim, A. A. Doye, and J. K. Gwathmey, "Contribution of abnormal sarcoplasmic reticulum ATPase activity to systolic and diastolic dysfunction in human heart failure," Journal of Molecular and Cellular Cardiology, vol. 30, no. 10, pp. 1929-1937, 1998.

[7] D. M. Bers, "Calcium and cardiac rhythms: physiological and pathophysiological," Circulation Research, vol. 90, no. 1, pp. 1417, 2002.

[8] S. Kobayashi, M. Yano, T. Suetomi et al., "Dantrolene, a therapeutic agent for malignant hyperthermia, markedly improves the function of failing cardiomyocytes by stabilizing interdomain interactions within the ryanodine receptor," Journal of the American College of Cardiology, vol. 53, no. 21, pp. 1993-2005, 2009.

[9] C. C. Chou, M. S. Wen, H. L. Lee et al., "Dantrolene suppresses ventricular ectopy and arrhythmogenicity with acute myocardial infarction in a Langendorff-perfused pacing-induced heart failure rabbit model," Journal of Cardiovascular Electrophysiology, vol. 25, no. 4, pp. 431-439, 2014.

[10] E. O. B. Ortiz, K. Carvajal, and D. Cruz, "Protective effect of dantrolene in post-ischemic-reperfusion myocardial damage," Archivos del Instituto de Cardiología de México, vol. 69, no. 4, pp. 311-319, 1999.

[11] A. Pelleg, A. Roth, B. Shargordsky, B. Belhassen, A. Chagnac, and S. Laniado, "Effects of dantrolene sodium on occlusion and reperfusion arrhythmias in the canine heart," Methods and Findings in Experimental and Clinical Pharmacology, vol. 7, no. 5, pp. 239-243, 1985.

[12] B. Preckel, W. Schlack, T. Comfère, and V. Thämer, "Effect of dantrolene in an in vivo and in vitro model of myocardial reperfusion injury," Acta Anaesthesiologica Scandinavica, vol. 44, no. 2, pp. 194-201, 2000.

[13] C.-C. Chou, P.-C. Chang, M.-S. Wen et al., "Piceatannol facilitates conduction block and ventricular fibrillation induction in ischemia-reperfused rabbit hearts with pacing-induced heart failure," International Journal of Cardiology, vol. 171, no. 2, pp. 250-258, 2014.

[14] C.-C. Chou, S. Zhou, H. Hayashi et al., "Remodelling of action potential and intracellular calcium cycling dynamics during subacute myocardial infarction promotes ventricular arrhythmias in Langendorff-perfused rabbit hearts," Journal of Physiology, vol. 580, no. 3, pp. 895-906, 2007.

[15] H.-L. Lee, P.-C. Chang, C.-C. Chou et al., "Blunted proarrhythmic effect of nicorandil in a langendorff-perfused phase2 myocardial infarction rabbit model," PACE-Pacing and Clinical Electrophysiology, vol. 36, no. 2, pp. 142-151, 2013.

[16] X. Wan, K. R. Laurita, E. J. Pruvot, and D. S. Rosenbaum, "Molecular correlates of repolarization alternans in cardiac myocytes," Journal of Molecular and Cellular Cardiology, vol. 39, no. 3, pp. 419-428, 2005.

[17] K. R. Laurita, R. Katra, B. Wible, X. Wan, and M. H. Koo, "Transmural heterogeneity of calcium handling in canine," Circulation Research, vol. 92, no. 6, pp. 668-675, 2003.
[18] A. D. Sharma, J. E. Saffitz, B. I. Lee, B. E. Sobel, and P. B. Corr, "Alpha adrenergic-mediated accumulation of calcium in reperfused myocardium," The Journal of Clinical Investigation, vol. 72, no. 3, pp. 802-818, 1983.

[19] M. Ono, M. Yano, A. Hino et al., "Dissociation of calmodulin from cardiac ryanodine receptor causes aberrant $\mathrm{Ca}^{2+}$ release in heart failure," Cardiovascular Research, vol. 87, no. 4, pp. 609617, 2010.

[20] Z. Vera, H. P. Pride, and D. P. Zipes, "Reperfusion arrhythmias: role of early afterdepolarizations studied by monophasic action potential recordings in the intact canine heart during autonomically denervated and stimulated states," Journal of Cardiovascular Electrophysiology, vol. 6, no. 7, pp. 532-543, 1995.

[21] R. Yee, K. K. Brown, D. E. Bolster, and H. C. Strauss, "Relationship between ionic perturbations and electrophysiologic changes in a canine Purkinje fiber model of ischemia and reperfusion," Journal of Clinical Investigation, vol. 82, no. 1, pp. 225-233, 1988.

[22] G. R. Ferrier, M. P. Moffat, and A. Lukas, "Possible mechanisms of ventricular arrhythmias elicited by ischemia followed by reperfusion. Studies on isolated canine ventricular tissues," Circulation Research, vol. 56, no. 2, pp. 184-194, 1985.

[23] J. J. Salata and J. Jalife, "Effects of dantrolene sodium on the electrophysiological properties of canine cardiac Purkinje fibers," Journal of Pharmacology and Experimental Therapeutics, vol. 220, no. 1, pp. 157-166, 1982.

[24] R. R. Brooks, J. F. Carpenter, S. M. Jones, and C. M. Gregory, "Effects of dantrolene sodium in rodent models of cardiac arrhythmia," European Journal of Pharmacology, vol. 164, no. 3, pp. 521-530, 1989.

[25] R. M. Temsah, T. Netticadan, D. Chapman, S. Takeda, S. Mochizuki, and N. S. Dhalla, "Alterations in sarcoplasmic reticulum function and gene expression in ischemic-reperfused rat heart," American Journal of Physiology: Heart and Circulatory Physiology, vol. 277, no. 2, pp. H584-H594, 1999.

[26] P. A. Penkoske, B. E. Sobel, and P. B. Corr, "Disparate electrophysiological alterations accompanying dysrhythmia due to coronary occlusion and reperfusion in the cat," Circulation, vol. 58, no. 6, pp. 1023-1035, 1978.

[27] C. Ding, X.-H. Fu, Z.-S. He, H.-X. Chen, L. Xue, and J.-X. Li, "Cardioprotective effects of simvastatin on reversing electrical remodeling induced by myocardial ischemia-reperfusion in normocholesterolemic rabbits," Chinese Medical Journal, vol. 121, no. 6, pp. 551-556, 2008.

[28] S. Dhein, "Gap junction channels in the cardiovascular system: pharmacological and physiological modulation," Trends in Pharmacological Sciences, vol. 19, no. 6, pp. 229-241, 1998.

[29] J. J. Salata, J. A. Wasserstrom, and J. Jalife, "Dantrolene sodium: effects on isolated cardiac tissues," Journal of Molecular and Cellular Cardiology, vol. 15, no. 4, pp. 233-243, 1983.

[30] P. L. Rensma, M. A. Allessie, W. J. E. P. Lammers, F. I. M. Bonke, and M. J. Schalij, "Length of excitation wave and susceptibility to reentrant atrial arrhythmias in normal conscious dogs," Circulation Research, vol. 62, no. 2, pp. 395-410, 1988.

[31] J. N. Weiss, Z. Qu, P. S. Chen et al., "The dynamics of cardiac fibrillation," Circulation, vol. 112, no. 8, pp. 1232-1240, 2005. 
[32] J. N. Weiss, M. Nivala, A. Garfinkel, and Z. Qu, "Alternans and arrhythmias: from cell to heart," Circulation Research, vol. 108, no. 1, pp. 98-112, 2011.

[33] A. Yao, S. U. Zhi, A. Nonaka et al., "Abnormal myocyte $\mathrm{Ca}^{2+}$ homeostasis in rabbits with pacing-induced heart failure," American Journal of Physiology - Heart and Circulatory Physiology, vol. 275, no. 4, pp. H1441-H1448, 1998. 


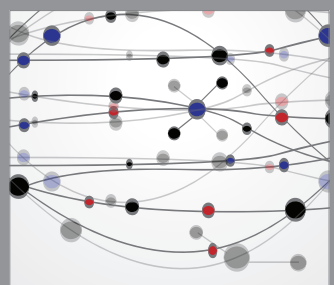

The Scientific World Journal
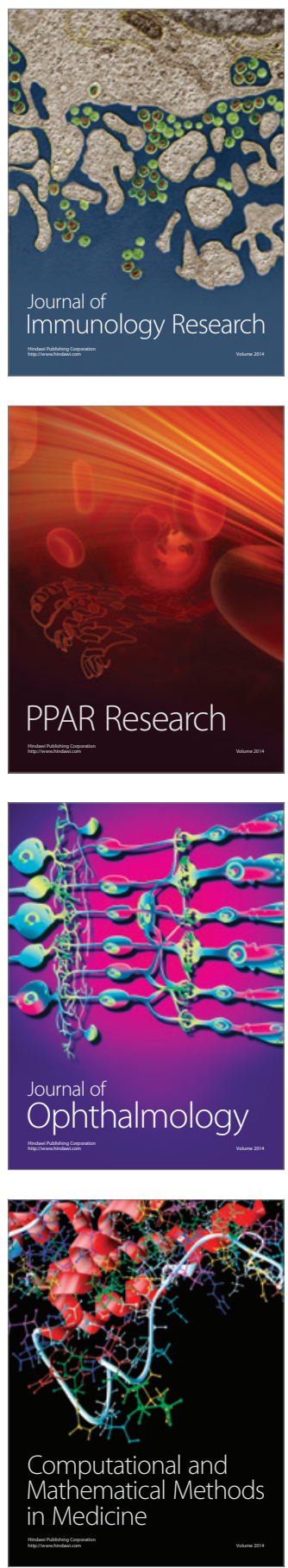

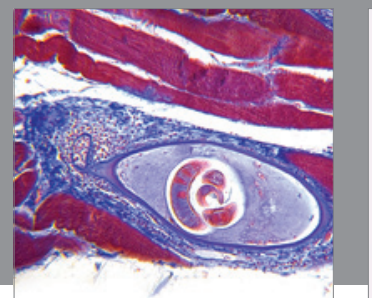

Gastroenterology

Research and Practice
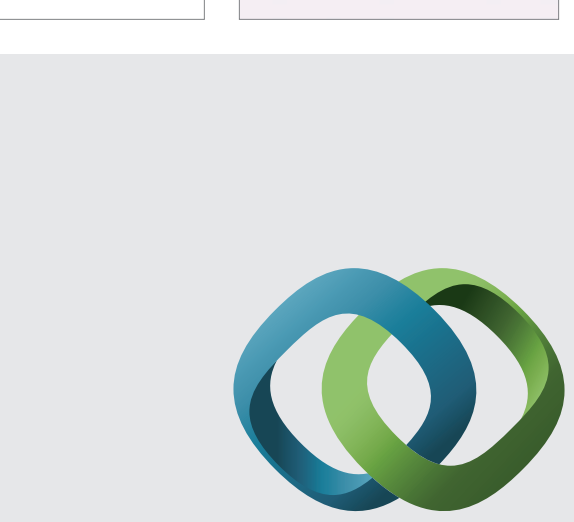

\section{Hindawi}

Submit your manuscripts at

http://www.hindawi.com
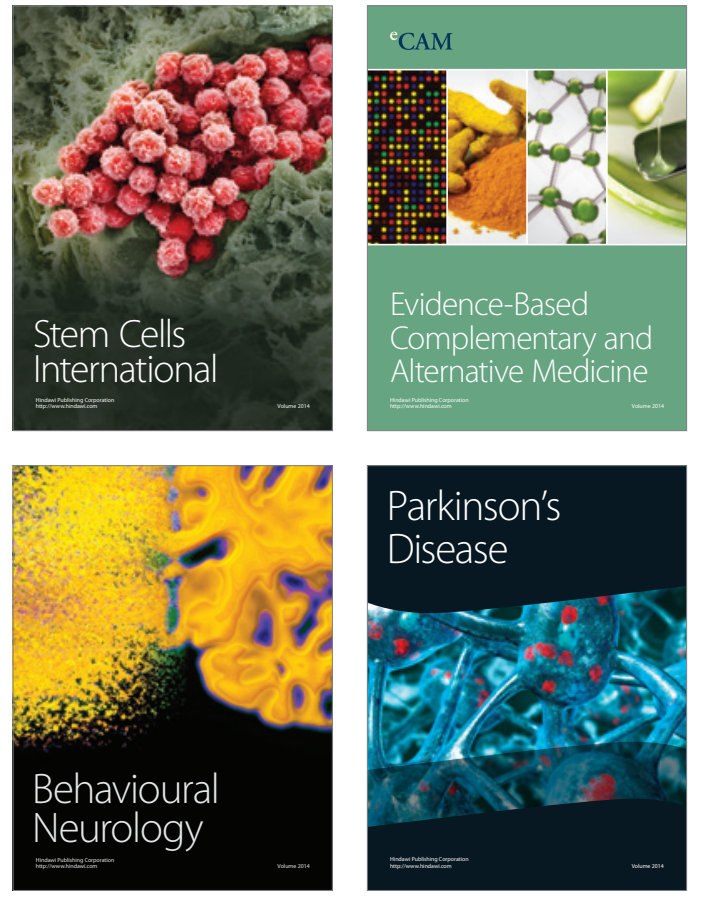
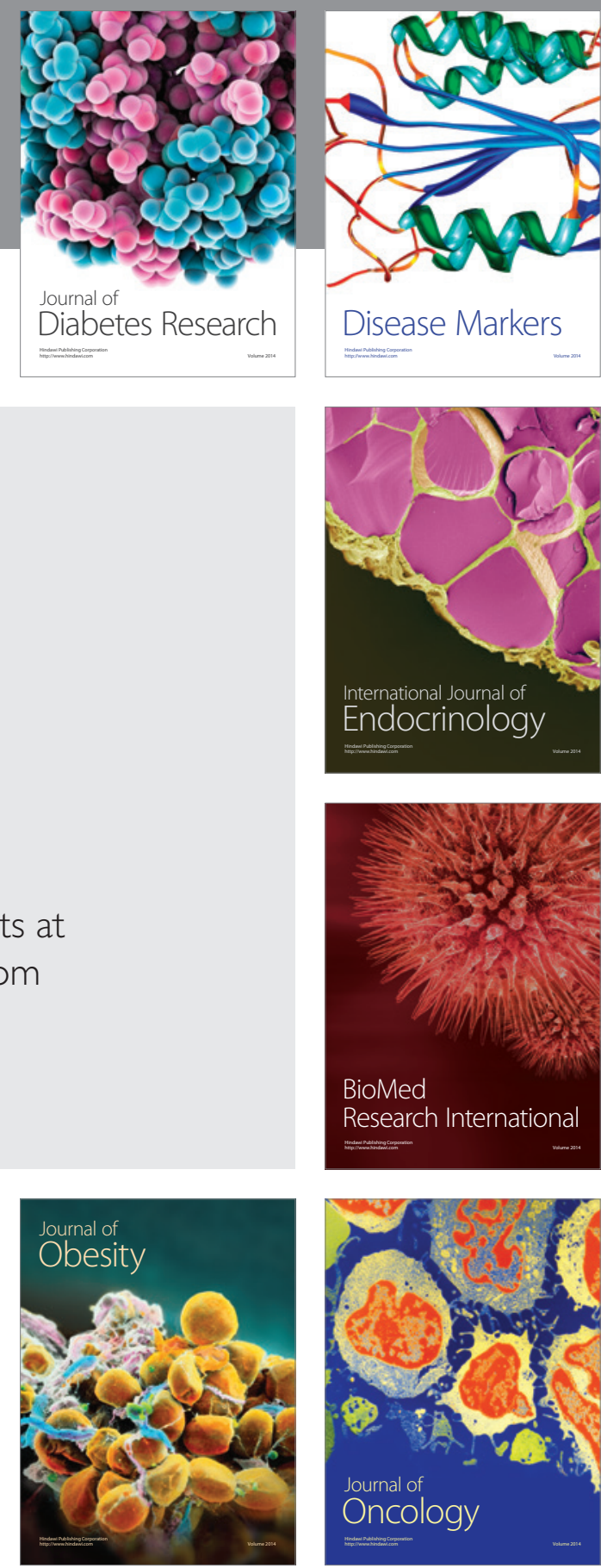

Disease Markers
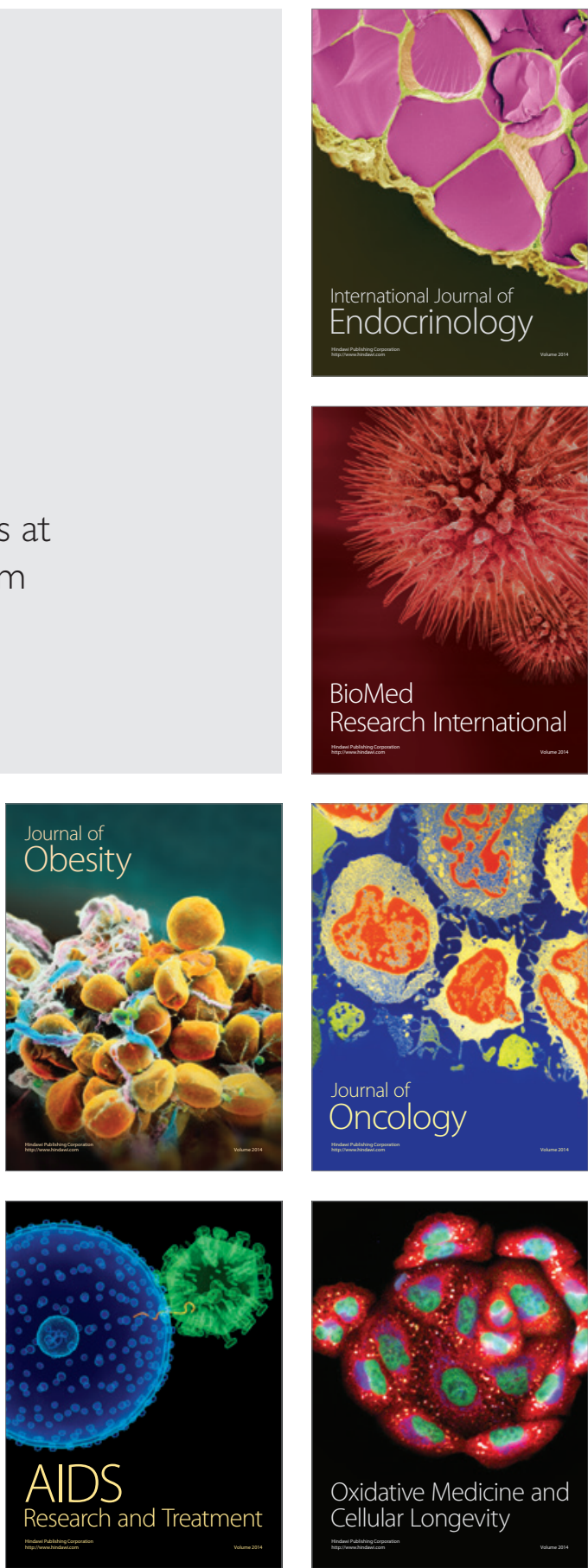